\title{
Technical Note: Antimicrobial Susceptibility of Portuguese Isolates of Staphylococcus aureus and Staphylococcus epidermidis in Subclinical Bovine Mastitis
}

\author{
S. F. Nunes, ${ }^{1}$ R. Bexiga, L. M. Cavaco, and C. L. Vilela \\ Centro de Investigação Interdisciplinar em Sanidade Animal (CIISA), Faculdade de Medicina Veterinária, Av. Universidade Técnica, \\ 1300-477 Lisbon, Portugal
}

\section{ABSTRACT}

To evaluate the antimicrobial resistance traits of staphylococci responsible for subclinical bovine mastitis in Portugal, the minimum inhibitory concentrations (MIC) of 7 antimicrobial agents, frequently administered for mastitis treatment, were determined for 30 Staphylococcus aureus and 31 Staphylococcus epidermidis field isolates. $\beta$-Lactamase production was detected through the use of nitrocefin-impregnated discs. The MIC that inhibited $90 \%$ of the isolates tested $\left(\mathrm{MIC}_{90}\right)$ of penicillin, oxacillin, cefazolin, gentamicin, sulfamethoxazole/trimethoprim, oxytetracycline, and enrofloxacin were, respectively, 4, 0.5, 1, 1, 0.25, 0.25, and $0.06 \mu \mathrm{g} / \mathrm{mL}$ for Staph. aureus and $\geq 64,8,1,32$, $\geq 64, \geq 64$, and $0.06 \mu \mathrm{g} / \mathrm{mL}$ for Staph. epidermidis. All Staph. aureus isolates showed susceptibility to oxacillin, cefazolin, gentamicin, sulphamethoxazole/trimethoprim, and enrofloxacin. $\beta$-Lactamase production was detected in 20 of these isolates (66.7\%), all of which were resistant to penicillin. Of the 31 Staph. epidermidis tested, 24 (77.4\%) were $\beta$-lactamase positive. All isolates were susceptible to both cefazolin and enrofloxacin. Nine Staph. epidermidis isolates were resistant to oxacillin, with MIC values ranging from 4 to 8 $\mu \mathrm{g} / \mathrm{mL}$. The MIC values of 5 antimicrobial agents tested were higher than those reported in other countries. Enrofloxacin was the only exception, showing lower MIC values compared with other reports. Overall, the antimicrobial agents tested in our study, with the exception of penicillin, were active against the 61 isolates studied.

Key words: bovine mastitis, antimicrobial susceptibility, Staphylococcus aureus, Staphylococcus epidermidis

Bovine mastitis remains the most costly disease affecting dairy cows and milk production worldwide. Mi-

Received November 7, 2006.

Accepted March 19, 2007.

${ }^{1}$ Corresponding author: amsandronunes@fmv.utl.pt crorganisms such as Staphylococcus aureus, Streptococcus agalactiae, and Streptococcus dysgalactiae are considered major pathogens, due to their prevalence in dairy herds, contagious nature of infection, and economic impact of treatment and control. Minor pathogens include CNS such as Staphylococcus epidermidis, Staphylococcus xylosus, and Staphylococcus chromogenes and are considered to infect the mammary gland from an environmental source. The CNS are the most frequently isolated bacteria from mastitic milk, more frequent in samples from first lactation and from unbred dairy heifers. The CNS have been implicated in a large proportion of dry period and early lactation mastitis episodes (Rajala-Schultz et al., 2004). They may be responsible for both clinical and subclinical disease even though their role as subclinical pathogens is more often emphasized. Whenever preventive measures fail, antimicrobial therapy is a useful tool for the control of clinical, subclinical, and recurrent IMI in both lactating and dry dairy cows. Information on the prevalence and antimicrobial susceptibility of mastitis pathogens becomes crucial for a successful and rational mastitis control program. In the central region of Portugal, Staph. aureus and Staph. epidermidis have been identified as 2 of the most prevalent pathogens associated with subclinical mastitis in dairy cows (Bexiga et al., 2005). Until now, mastitis-specific susceptibility breakpoints were available only for pirlimycin and the penicillin/ novobiocin combination. Updated information on MIC values for mastitis pathogens from different origins is continuously required to validate the clinical relevance of in vitro susceptibility testing results of these pathogens.

The aim of the present study was to determine the MIC of 7 antimicrobial drugs commonly used in mastitis control of subclinical mastitis isolates of Staph. aureus and Staph. epidermidis in Portugal. Thirty Staph. aureus and 31 Staph. epidermidis isolated from bovine intramammary subclinical infections, detected by the California Mastitis Test, were used in this study. Isolates were obtained from quarter milk samples from 7 
Table 1. Dilution range and susceptibility breakpoints of 7 antimicrobial drugs used in the treatment of subclinical mastitis

\begin{tabular}{lcccc}
\hline & \multirow{2}{*}{$\begin{array}{c}\text { Dilution } \\
\text { range }\end{array}$} & \multicolumn{2}{c}{ Susceptibility breakpoints $(\mu \mathrm{g} / \mathrm{mL})$} \\
\cline { 3 - 5 } & $(\mu \mathrm{g} / \mathrm{mL})$ & Susceptible & Intermediate & Resistant \\
\hline Antimicrobial agent & $0.03-64$ & $\leq 0.12$ & & $\geq 0.25$ \\
Penicillin & $0.03-64$ & $\leq 2$ & & $\geq 4$ \\
Oxacillin & $0.03-64$ & $\leq 8$ & 16 & $\geq 32$ \\
Cefazolin $^{1}$ & $0.03-64$ & $\leq 4$ & 8 & $\geq 16$ \\
Gentamicin $_{\text {Sulfamethoxazole/trimethoprim }}$ & $0.03-64$ & $\leq 38 / 2$ & & $\geq 76 / 4$ \\
Oxytetracycline $^{1,2}$ & $0.03-64$ & $\leq 4$ & 8 & $\geq 16$ \\
Enrofloxacin & $0.03-16$ & $\leq 0.25$ & $0.5-1$ & $\geq 2$ \\
\hline
\end{tabular}

${ }^{1}$ Susceptibility breakpoints based on human data.

${ }^{2}$ Oxytetracycline breakpoints were based on the class representative tetracycline (document M31-A2; CLSI, 2002).

commercial dairy farms of the Ribatejo-Oeste region of Portugal (Bexiga et al., 2005). Sample collection and bacterial isolation were performed according to the $\mathrm{Na}$ tional Mastitis Council recommendations (NMC, 1987).

The MIC of penicillin, oxacillin, cefazolin, gentamicin, sulfamethoxazole/trimethoprim, oxytetracycline, and enrofloxacin were determined by broth microdilution, following the Clinical and Laboratory Standards Institute standards for veterinary susceptibility testing (CLSI, 2002). Antimicrobial agents were purchased as standard powders from Sigma, with exception of enrofloxacin, which was kindly supplied by Bayer Animal Health (Carbaxide, Portugal). Sulfamethoxazole and trimethoprim were tested in a 5:1 ratio ( $\mathrm{vol} / \mathrm{vol}$ ) as available in commercial drugs for mastitis treatment.

Ten 2-fold dilutions of each drug were prepared in Mueller-Hinton broth (Oxoid, Basingstoke, UK) and distributed in 96-well microtitres plates (Nunc, Wiesbaden, Germany). Before testing, isolates were revived by plating twice on Columbia agar (bioMérieux, Marcy

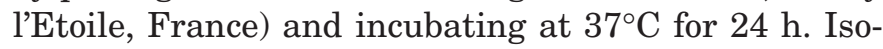
lated colonies were suspended in Mueller-Hinton broth, adjusted by optical density, distributed into wells to a final concentration of $5 \times 10^{5} \mathrm{cfu} / \mathrm{mL}$, and incubated at $37^{\circ} \mathrm{C}$ for $22 \pm 2 \mathrm{~h}$ under aerobic conditions. All isolates were tested at least twice in separate occasions. Reference strain Staph. aureus ATCC 29213 was used for quality control purposes. The dilution range and susceptibility breakpoints used, based on CLSI standards (document M31-A2; CLSI, 2002) are described in Table 1 .

$\beta$-Lactamase production testing of isolates was performed using nitrocefin-impregnated Cefinase discs (Becton Dickinson Microbiology Systems, Devon, UK) in accordance with the manufacturer's instructions for staphylococcal testing. Staphylococcus aureus ATCC 29213 and Staphylococcus aureus ATCC 25923 were used as positive and negative controls, respectively. The MIC distribution and $\mathrm{MIC}_{50}$ and $\mathrm{MIC}_{90}$ values (MIC that inhibited 50 and $90 \%$ of the isolates tested, respectively) of the 7 antimicrobial drugs tested for Staph. aureus and Staph. epidermidis field isolates are summarized, respectively, in Tables 2 and 3. The MIC values for the quality control organism were within recommended ranges for all the antimicrobial agents tested; cephalothin ranges were used for cefazolin (CLSI, 2002)

Several studies have reported the in vitro antimicrobial susceptibility of Staph. aureus and CNS isolated from bovine IMI (Watts and Salmon, 1997; De Oliveira et al., 2000; Devriese et al., 2002; Gentilini et al., 2000, 2002; Yoshimura et al., 2002; Guerin-Faublee et al., 2003; Pengov and Ceru, 2003; Luthje and Schwarz, 2006). However, data gathered from Portuguese isolates is limited. Recent information on the susceptibility traits is essential for antimicrobial resistance monitoring and could help to accurately define specific breakpoints for mastitis pathogens, which are still unavailable for the majority of the antimicrobial agents administered for IMI control. The majority of breakpoints for staphylococci testing is based on human data and does not take into account the specificity of the udder environment. Consequently, special care should be taken when evaluating the antimicrobial susceptibility of IMI subclinical mastitis bacterial isolates based in these breakpoints.

All of the Staph. aureus isolates tested were susceptible to oxacillin, cefazolin, gentamicin, sulphamethoxazole/trimethoprim, and enrofloxacin. Production of $\beta$ lactamase was detected in 20 isolates $(66.7 \%)$, all of which were resistant to penicillin. The isolate with the highest MIC value for penicillin $(16 \mu \mathrm{g} / \mathrm{mL})$ was also the only oxytetracycline-resistant strain. Of the 31 Staph. epidermidis isolates tested, $24(77.4 \%)$ showed $\beta$-lactamase production. All isolates were considered susceptible to cefazolin and enrofloxacin. High levels of resistance to penicillin, gentamicin, and oxytetracycline were found. 
Table 2. Distribution of MIC of penicillin, oxacillin, cefazolin, gentamicin, sulfamethoxazole/trimethoprim, oxytetracycline, and enrofloxacin to 30 Staphylococcus aureus isolates from subclinical mastitis in 7 farms from the central region of Portugal ${ }^{1}$

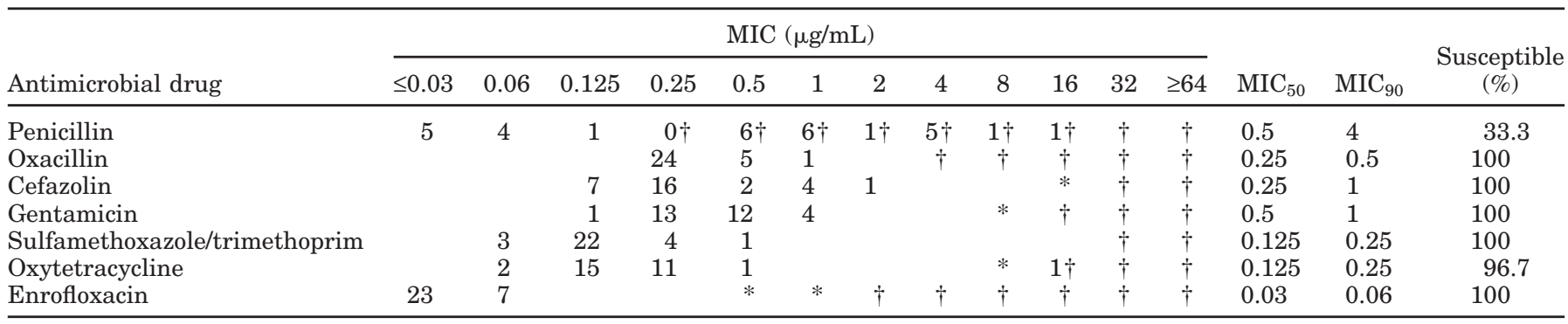

${ }^{1}$ Boxes marked with an asterisk $(*)$ indicate MIC values that correspond to intermediate antimicrobial susceptibility; boxes marked with a dagger ( $\dagger$ ) indicate MIC values that correspond to antimicrobial resistance.

Penicillin susceptibility testing predicts the susceptibility to other $\beta$-lactamase-sensitive antimicrobial drugs, such as ampicillin and amoxicillin. In the present study, levels of penicillin resistance were higher than in other countries. The $\mathrm{MIC}_{90}$ values of penicillin described for Staph. aureus isolated from bovine mastitis range from $\leq 0.06 \mu \mathrm{g} / \mathrm{mL}$ in Norway to $4 \mu \mathrm{g} / \mathrm{mL}$ in New Zealand, the latter equal to the value found in our study. However, the most frequent $\mathrm{MIC}_{90}$ value reported in the literature is $0.5 \mu \mathrm{g} / \mathrm{mL}$ (Watts et al., 1995; Salmon et al., 1998; De Oliveira et al., 2000; Gentilini et al., 2000; Guerin-Faublee et al., 2003). The MIC values for penicillin for Staph. epidermidis are scarce, because CNS testing is seldom performed at the species level. Watts et al. (1995) reported a penicillin $\mathrm{MIC}_{90}$ of 0.5 $\mu \mathrm{g} / \mathrm{mL}$ for 28 Staph. epidermidis isolates. For this species, our study showed a $\mathrm{MIC}_{90} \geq 64 \mu \mathrm{g} / \mathrm{mL}$, a much higher value than that reported previously, even when all CNS are considered together (Owens et al., 1997; Salmon et al., 1998; Guerin-Faublee et al., 2003). The confirmation of $\beta$-lactamase production in conjunction with susceptibility testing can provide useful information on penicillin resistance. The fact that none of the susceptible isolates to penicillin of both species were $\beta$ lactamase producers indicate that the high levels of penicillin-resistance might be attributed to the produc- tion of these enzymes. In the present study, the percentage of isolates showing the ability to produce these enzymes is similar to that reported for isolates from Ireland and Iceland, respectively 63.6 and $76.2 \%$ (De Oliveira et al., 2000) and higher than the percentages found in Scandinavia, where antimicrobial drug use in humans and animals is carefully monitored and controlled (Myllys et al., 1998).

Although only cloxacillin is approved for intramammary administration in Portugal, oxacillin is the class representative recommended by CLSI for antimicrobial susceptibility testing and detection of methicillin resistance of staphylococcal strains. The $\mathrm{MIC}_{90}$ values obtained for Staph. aureus were similar to those found in other countries (Watts et al., 1995; De Oliveira et al., 2000; Gentilini et al., 2000, 2002; Guerin-Faublee et al., 2003). All 9 oxacillin-resistant isolates were also resistant to penicillin (MIC ranging from 2 to $\geq 64 \mu \mathrm{g} /$ $\mathrm{mL}$ ) and oxytetracycline (all with MIC $\geq 64 \mu \mathrm{g} / \mathrm{mL}$ ), and they were $\beta$-lactamase producers. Only one of these isolates showed susceptibility to gentamicin $(\mathrm{MIC}=$ $0.125 \mu \mathrm{g} / \mathrm{mL}$ ). Subsequent testing revealed that all 9 isolates were mecA carriers (data not shown; Nunes et al., 2006). Methicillin resistance in mastitis pathogens is still uncommon. In a study carried out by GuerinFaublee et al. (2003), only 1 out of 171 staphylococcal

Table 3. Distribution of MIC of penicillin, oxacillin, cefazolin, gentamicin, sulfamethoxazole/trimethoprim, oxytetracycline, and enrofloxacin to 31 Staphylococcus epidermidis isolates from subclinical mastitis in 7 farms from the central region of Portugal ${ }^{1}$

\begin{tabular}{|c|c|c|c|c|c|c|c|c|c|c|c|c|c|c|c|}
\hline Antimicrobial drug & \multicolumn{12}{|c|}{$\mathrm{MIC}(\mu \mathrm{g} / \mathrm{mL})$} & $\mathrm{MIC}_{50}$ & $\mathrm{MIC}_{90}$ & $\begin{array}{c}\text { Susceptible } \\
(\%)\end{array}$ \\
\hline Penicillin & & 3 & & $1 \dagger$ & $\dagger$ & $\dagger$ & $3 \dagger$ & $4 \dagger$ & $2 \dagger$ & $4 \dagger$ & $5 \dagger$ & $9 \dagger$ & 16 & $\geq 64$ & 9.7 \\
\hline Cefazolin & 2 & 3 & 5 & 7 & 7 & 7 & & & & & $\dagger$ & $\dagger$ & 0.25 & 1 & 100 \\
\hline Gentamicin & 2 & 6 & 2 & 1 & & & & & $5^{*}$ & $6 \dagger$ & $6 \dagger$ & $3 \dagger$ & 8 & 32 & 35.5 \\
\hline Sulfamethoxazole/trimethoprim & & 1 & 1 & 6 & 4 & 1 & 7 & 3 & 3 & & $\dagger$ & $5 \dagger$ & 2 & $\geq 64$ & 83.3 \\
\hline
\end{tabular}

${ }^{1}$ Boxes marked with an asterisk $(*)$ indicate MIC values that correspond to intermediate antimicrobial susceptibility; boxes marked with a dagger $(\dagger)$ indicate MIC values that correspond to antimicrobial resistance. 
mastitis isolates was methicillin resistant. De Oliveira et al. (2000) reported that none of 12 isolates with MIC values corresponding to oxacillin resistance possessed the $m e c A$ gene and that the resistance might be associated with hyperproduction of $\beta$-lactamase. Recently in Korea, higher levels of both methicillin resistance and mecA carriers were found in mastitis-related Staph. aureus and CNS (Moon et al., 2007). The presence of methicillin resistance in CNS isolates is of concern, because horizontal mecA gene transfer among different staphylococcal species has previously been reported (Archer et al., 1994).

In the present study, no resistance to cefazolin, a first-generation cephalosporin, was observed in any of the isolates of either species. The $\mathrm{MIC}_{90}$ was $1 \mu \mathrm{g} / \mathrm{mL}$, higher than the value observed in studies in France and Japan (Yoshimura et al., 2002; Guerin-Faublee et al., 2003). However, according to CLSI recommendations, all methicillin-resistant strains, such as the 9 found in this study, should be considered also resistant to penicillins and cephalosporins (CLSI, 2002).

Gentamicin has limited use in farm animal antimicrobial therapy due to the long withdrawal period in milk and meat. In our study, gentamicin showed good activity against Staph. aureus, with a $\mathrm{MIC}_{90}$ of $1 \mu \mathrm{g} /$ $\mathrm{mL}$, higher than that reported in Japan $(0.39 \mu \mathrm{g} / \mathrm{mL})$ but lower than in Argentina with $1.5 \mu \mathrm{g} / \mathrm{mL}$ (Gentilini et al., 2000; Yoshimura et al., 2002).

Our results showed good activity for the association of sulfamethoxazole with trimethoprim against Staph. aureus with a $\mathrm{MIC}_{90}$ of $0.25 \mu \mathrm{g} / \mathrm{mL}$. A greater number of resistant isolates was observed in Staph. epidermidis with $\mathrm{MIC}_{90}>64 \mu \mathrm{g} / \mathrm{mL}$. However, the MIC distribution showed a wide range of susceptibility ( 0.06 to $8 \mu \mathrm{g} / \mathrm{mL}$ ). This association was tested using a higher ratio than that recommended by the CLSI (19:1), which may be responsible for the high susceptibility levels observed in both species in this study.

In our study, no resistance to oxytetracycline was found in Staph. aureus, with a $\mathrm{MIC}_{90}$ of $0.25 \mu \mathrm{g} / \mathrm{mL}$, which was lower than that reported by Yoshimura et al. (2002) with a value of $1.56 \mu \mathrm{g} / \mathrm{mL}$. On the contrary, $>80 \%$ of Staph. epidermidis isolates were resistant, with both $\mathrm{MIC}_{50}$ and $\mathrm{MIC}_{90}>64 \mu \mathrm{g} / \mathrm{mL}$. The high levels of resistance of Staph. epidermidis to sulfamethoxazole/ trimethoprim and oxytetracycline could be due to the extended use of these drugs in dairy cows. The CNS are found in the normal microbiota of human skin and the bovine udder and teat canal. It could be argued that the resistance levels observed may be related to a selective pressure whenever antimicrobial therapy is used, although human transmission of resistant isolates may also occur.
The enrofloxacin $\mathrm{MIC}_{90}$ values of Staph. aureus and Staph. epidermidis found in this study (both $0.06 \mu \mathrm{g} /$ $\mathrm{mL}$ ) are much lower than those reported in other regions (Watts et al., 1995; Owens et al., 1997; Salmon et al., 1998; De Oliveira et al., 2000; Yoshimura et al., 2002). These high susceptibility levels to enrofloxacin may be due to its infrequent use in cattle, in either intramammary or systemic administration, for treatment of mastitis in Portugal. Finally, when comparing our results on antimicrobial resistance with the published data, special attention should be given to the possible influence of previous exposure to drugs. Most of our isolates were obtained from mature cows, but some heifers presented subclinical mastitis and these isolates were also included in this study. Therefore, previous mastitis episodes or preventive treatments may have influenced the MIC values registered.

Overall, with the exception of penicillin, the antimicrobial agents tested in our study demonstrated good activity against the 61 isolates studied. The MIC values of the antimicrobial agents tested were, in general, higher than those reported in other countries, except for enrofloxacin, which showed the lowest MIC values. The major differences observed in the resistance traits of the 2 species tested emphasize the importance of the bacterial identification of the pathogens in mastitis control. Among CNS, a minor mastitis pathogen, special attention should be given to the Staph. epidermidis, due to the high incidence of resistance found in general and in particular to methicillin resistance. The high number of $\beta$-lactamase-producing isolates found in our study suggests that the administration of $\beta$-lactams, especially penicillin and related drugs, should be carefully considered for mastitis control in the RibatejoOeste region.

\section{ACKNOWLEDGMENTS}

This study was conducted with the financial support of the "Centro de Investigação Interdisciplinar em Sanidade Animal" (CIISA/FMV) from the Faculdade de Medicina Veterinária, and by the Fundação de Ciência e Tecnologia - Project POCTI/CA/1995/95/2003. The authors thank Carla Carneiro for her excellent technical support.

\section{REFERENCES}

Archer, G. L., D. M. Niemeyer, J. A. Thanassi, and M. J. Pucci. 1994. Dissemination among staphylococci of DNA sequences associated with methicillin resistance. Antimicrob. Agents Chemother. 38:447-454.

Bexiga, R., L. M. Cavaco, and C. L. Vilela. 2005. Mastites subclínicas bovinas na zona do Ribatejo-Oeste. Revista da Sociedade Portuguesa de Ciências Veterinárias 100:39-44.

CLSI. 2002. Performance standards for antimicrobial disk and dilution susceptibility tests for bacteria isolated from animals; ap- 
proved standard. 2nd ed. Clinical and Laboratory Standards Institute, Wayne, PA.

De Oliveira, A. P., J. L. Watts, S. A. Salmon, and F. M. Aarestrup. 2000. Antimicrobial susceptibility of Staphylococcus aureus isolated from bovine mastitis in Europe and the United States. J. Dairy Sci. 83:855-862.

Devriese, L. A., M. Baele, M. Vaneechoutte, A. Martel, and F. Haesebrouck. 2002. Identification and antimicrobial susceptibility of Staphylococcus chromogenes isolates from intramammary infections of dairy cows. Vet. Microbiol. 87:175-182.

Gentilini, E., G. Denamiel, A. Betancor, M. Rebuelto, M. Rodriguez Fermepin, and R. A. De Torrest. 2002. Antimicrobial susceptibility of coagulase-negative staphylococci isolated from bovine mastitis in Argentina. J. Dairy Sci. 85:1913-1917.

Gentilini, E., G. Denamiel, P. Llorente, S. Godaly, M. Rebuelto, and O. DeGregorio. 2000. Antimicrobial susceptibility of Staphylococcus aureus isolated from bovine mastitis in Argentina. J. Dairy Sci. 83:1224-1227.

Guerin-Faublee, V., G. Carret, and P. Houffschmitt. 2003. In vitro activity of 10 antimicrobial agents against bacteria isolated from cows with clinical mastitis. Vet. Rec. 152:466-471.

Luthje, P., and S. Schwarz. 2006. Antimicrobial resistance of coagulase-negative staphylococci from bovine subclinical mastitis with particular reference to macrolide-lincosamide resistance phenotypes and genotypes. J. Antimicrob. Chemother. 57:966-969.

Moon, J. S., A. R. Lee, H. M. Kang, E. S. Lee, M. N. Kim, Y. H. Paik, Y. H. Park, Y. S. Joo, and H. C. Koo. 2007. Phenotypic and genetic antibiogram of methicillin-resistant staphylococci isolated from bovine mastitis in Korea. J. Dairy Sci. 90:1176-1185.

Myllys, V., K. Asplund, E. Brofeldt, V. Hirvela-Koski, T. HonkanenBuzalski, J. Junttila, L. Kulkas, O. Myllykangas, M. Niskanen, H. Saloniemi, M. Sandholm, and T. Saranpaa. 1998. Bovine mastitis in Finland in 1988 and 1995-Changes in prevalence and antimicrobial resistance. Acta Vet. Scand. 39:119-126.
NMC. 1987. Laboratory Handbook on Bovine Mastitis. National Mastitis Council, Verona, WI.

Nunes, S. F., I. Couto, R. Bexiga, M. Oliveira, L. M. Cavaco, H. Lencastre, and C. L. Vilela. 2006. Screening of methicillin-resistance in bovine mastitis staphylococci. Proc. World Buiatrics Congr. 2006, Nice, France. World Association for Buiatrics.

Owens, W. E., C. H. Ray, J. L. Watts, and R. J. Yancey. 1997. Comparison of success of antibiotic therapy during lactation and results of antimicrobial susceptibility tests for bovine mastitis. J. Dairy Sci. 80:313-317.

Pengov, A., and S. Ceru. 2003. Antimicrobial drug susceptibility of Staphylococcus aureus strains isolated from bovine and ovine mammary glands. J. Dairy Sci. 86:3157-3163.

Rajala-Schultz, P. J., K. L. Smith, J. S. Hogan, and B. C. Love. 2004. Antimicrobial susceptibility of mastitis pathogens from first lactation and older cows. Vet. Microbiol. 102:33-42.

Salmon, S. A., J. L. Watts, F. M. Aarestrup, J. W. Pankey, and R. J. Yancey, Jr. 1998. Minimum inhibitory concentrations for selected antimicrobial agents against organisms isolated from the mammary glands of dairy heifers in New Zealand and Denmark. J. Dairy Sci. 81:570-578.

Watts, J. L., and S. A. Salmon. 1997. Activity of selected antimicrobial agents against strains of Staphylococcus aureus isolated from bovine intramammary infections that produce $\beta$-lactamase. J. Dairy Sci. 80:788-791.

Watts, J. L., S. A. Salmon, R. J. Yancey, Jr., S. C. Nickerson, L. J. Weaver, C. Holmberg, J. W. Pankey, and L. K. Fox. 1995. Antimicrobial susceptibility of microorganisms isolated from the mammary glands of dairy heifers. J. Dairy Sci. 78:1637-1648.

Yoshimura, H., M. Ishimaru, and A. Kojima. 2002. Minimum inhibitory concentrations of 20 antimicrobial agents against Staphylococcus aureus isolated from bovine intramammary infections in Japan. J. Vet. Med. B 49:457-460. 